\title{
Behavioral Comorbidities and Drug Treatments in a Zebrafish scn1lab Model of Dravet Syndrome
}

\author{
(1)Brian P. Grone, ${ }^{1}$ (1) Tiange Qu, ${ }^{1,2}$ and ${ }^{1}$ Scott C. Baraban ${ }^{1,2,3}$
}

DOI:http://dx.doi.org/10.1523/ENEURO.0066-17.2017

${ }^{1}$ Epilepsy Research Laboratory in the Department of Neurological Surgery, University of California, San Francisco, $\mathrm{CA},{ }^{2}$ Helen Wills Neuroscience Institute, University of California, Berkeley, CA, and ${ }^{3}$ Weill Institute for Neurosciences, University of California, San Francisco, San Francisco, CA 94143

\begin{abstract}
Loss-of-function mutations in SCN1A cause Dravet syndrome (DS), a catastrophic childhood epilepsy in which patients experience comorbid behavioral conditions, including movement disorders, sleep abnormalities, anxiety, and intellectual disability. To study the functional consequences of voltage-gated sodium channel mutations, we use zebrafish with a loss-of-function mutation in scn1lab, a zebrafish homolog of human SCN1A. Homozygous scn1/ab ${ }^{5552 / s 552}$ mutants exhibit early-life seizures, metabolic deficits, and early death. Here, we developed in vivo assays using scn1lab ${ }^{\text {s552 }}$ mutants between 3 and $6 \mathrm{~d}$ postfertilization (dpf). To evaluate sleep disturbances, we monitored larvae for $24 \mathrm{~h}$ with locomotion tracking software. Locomotor activity during dark (night phase) was significantly higher in mutants than in controls. Among anticonvulsant drugs, clemizole and diazepam, but not trazodone or valproic acid, decreased distance moved at night for scn1lab ${ }^{5552}$ mutant larvae. To monitor exploratory behavior in an open field, we tracked larvae in a novel arena. Mutant larvae exhibited impaired exploratory behavior, with increased time spent near the edge of the arena and decreased mobility, suggesting greater anxiety. Both clemizole and diazepam, but not trazodone or valproic acid, decreased distance moved and increased time spent in the center of the arena. Counting inhibitory neurons in vivo revealed no differences between $s c n 1 / a b^{5552}$ mutants and siblings. Taken together, our results demonstrate conserved features of sleep, anxiety, and movement disorders in scn1lab mutant zebrafish, and provide evidence that a zebrafish model allows effective tests of treatments for behavioral comorbidities associated with DS.
\end{abstract}

Key words: anxiety; Dravet syndrome; epilepsy; sleep; sodium channels; zebrafish

\section{Significance Statement}

Certain mutations cause severe genetic diseases that affect brain development, leading to seizures, cognitive impairment, and abnormal behaviors in affected children. One of the best studied of these genetic diseases is Dravet syndrome (DS), which results from mutations in a channel that normally controls sodium flux in the brain. Although the genetic cause of DS is known, no effective treatment is available. Animals, including zebrafish, share sodium channels that are similar to the human ones, and mutating a sodium channel also leads to an epilepsy disorder in developing zebrafish. We found that zebrafish with a DS-like mutation also exhibit problems with locomotion, sleep, and anxiety, and that these behaviors were modulated by antiepileptic drugs.

\section{Introduction}

Voltage-gated sodium channels are responsible for generation and propagation of neuronal action potentials

Received February 28, 2017; accepted July 30, 2017; First published August 03, 2017.

The authors declare no competing financial interests. in central and peripheral nervous systems. Mutations of these channels are a major cause of genetically inherited epilepsies and other neurologic disorders (Dichgans 
et al., 2005; Meisler and Kearney, 2005; Catterall, 2014; Waxman et al., 2014). SCN1A, which encodes the poreforming alpha subunit of $\mathrm{Na}_{\mathrm{v}} 1.1$, is expressed throughout mammalian nervous systems, primarily in axon initial segments and nodes of Ranvier (Gordon et al., 1987; Duflocq et al., 2008). Confirming the conserved importance of $\mathrm{Na}_{\mathrm{v}} 1.1$ for neural function, homologs of SCN1A are present in other vertebrates, including teleost fishes (Novak et al., 2006a,b; Widmark et al., 2011).

Nonsense and missense mutations in SCN1A are associated with a catastrophic epilepsy of childhood known as Dravet syndrome (DS; Escayg et al., 2000; Claes et al., 2001; Sugawara et al., 2002; Harkin et al., 2007; Depienne et al., 2009; Dravet, 2011; Catterall, 2014). In DS, seizures commonly appear in the first year of life (often accompanied by fever), and progress to prolonged myoclonic, atypical absence, or focal events with frequent status epilepticus episodes requiring emergency care (Gataullina and Dulac, 2017). Generalized and multifocal abnormalities are seen in the electroencephalography. Starting as early as the second year of life, DS children develop comorbid conditions such as psychomotor regression, motor disorder, abnormal sleep microarchitecture, and intellectual disability (Nolan et al., 2006; Martin et al., 2010; Dhamija et al., 2014). The risk for premature death is also high in this patient population (Genton et al., 2011). Unfortunately, effective treatments are not available to address the range of seizure phenotypes and comorbidities associated with DS (Chiron and Dulac, 2011; Catterall, 2014; Wilmshurst et al., 2014). Studies in animal models, which now include zebrafish as well as mice, offer a means to address this problem (Catterall, 2014; Grone and Baraban, 2015; Kaplan et al., 2016).

Mice with heterozygous deletion of Scn1a reproduce many DS phenotypes, including epilepsy with early onset (Yu et al., 2006; Ogiwara et al., 2007), susceptibility to febrile seizures (Oakley et al., 2009), sleep and circadian abnormalities (Han et al., 2012a; Papale et al., 2013), and premature death (Kalume et al., 2013). Reduced neuronal excitability and behavioral abnormalities are also found in Scn1a mutant mice (Han et al., 2012b; Ito et al., 2013). Although mice offer strengths for understanding the basic biology and physiology of ion channels and for testing treatments, they are not ideally suited to drug discovery.

This work was supported by the National Institutes of Health Grant 5R01NS079214 (to S.C.B.).

Acknowledgements: We thank Matthew Dinday and Kyla Hamling for outstanding technical assistance; Aleisha Griffin for helpful comments on a version of this manuscript; an Shih-Wei (Victoria) Chou, Holly Aaron, and Ehud Isacoff for assistance and support with light sheet imaging microscopy. S.C.B. is a Visiting Scholar in the Helen Wills Neuroscience Institute at the University of California, Berkeley. S.C.B. is cofounder and a scientific advisor to EpyGenix Therapeutics.

Correspondence should be addressed to Brian P. Grone at the above address, E-mail: brian.grone@ucsf.edu.

DOI:http://dx.doi.org/10.1523/ENEURO.0066-17.2017

Copyright (C) 2017 Grone et al.

This is an open-access article distributed under the terms of the Creative Commons Attribution 4.0 International license, which permits unrestricted use, distribution and reproduction in any medium provided that the original work is properly attributed.
Zebrafish have emerged as a powerful model organism for analyzing genetic diseases (Ablain and Zon, 2013; Deciphering Developmental Disorders Study, 2015; Grone et al., 2016; Tuschl et al., 2016). Zebrafish with a missense loss-of-function mutation in scn1lab, one of two SCN1Alike genes found in teleost fishes (Novak et al., 2006b), show oculomotor defects, early life seizures, pharmacoresistance, and metabolic deficits (Schoonheim et al., 2010; Baraban et al., 2013; Kumar et al., 2016; Sourbron et al., 2016). Like Scn1a null mice, which develop ataxia and die at about postnatal day 15 (Yu et al., 2006; Ogiwara et al., 2007), homozygous scn1/ab $b^{5552 / s 552}$ mutant larvae do not survive beyond $14 \mathrm{~d}$ postfertilization (dpf; Schoonheim et al., 2010). This well-conserved overall phenotype suggests that the scn1lab gene in zebrafish shares essential conserved functions with mammalian Scn1a. Whether scn1lab mutant zebrafish exhibit comorbidities normally associated with DS, including movement disorders, anxiety, or sleep disturbances, is not known. Here, we provide the first assessments of these behaviors in a zebrafish model of DS, i.e., scn1lab ${ }^{\mathrm{s5} 2}$ mutants. We used a set of assays based on zebrafish sleep patterns (Zhdanova et al., 2001; Yokogawa et al., 2007; Rihel et al., 2010), and behavioral responses to novel environments (Richendrfer et al., 2012; Schnörr et al., 2012; Ahmad and Richardson, 2013). We found that the homozygous scn1lab ${ }^{\text {s552 }}$ mutants exhibit nighttime hyperactivity, decreased time spent in the center of an open arena, and decreased responsiveness to sudden darkness. Diazepam and clemizole have previously been found to suppress convulsive seizure behaviors in this model (Baraban et al., 2013; Griffin et al., 2017). We found that both of these drugs also reduced nighttime locomotor activity and the time spent in the center of the open field. Taken together, our results suggest that behavioral comorbidities can be studied in larval zebrafish models of genetic epilepsies, and that these mutant fish could aid in identifying new treatments.

\section{Materials and Methods}

\section{Zebrafish maintenance}

Adult male and female zebrafish were maintained according to standard procedures (Westerfield, 2000) and following guidelines approved for this study by the University of California, San Francisco Institutional Animal Care and Use Committee. The $\operatorname{Tg}(1.4 d l \times 5 a-d l \times 6 a: G F P)$ fish line has been previously described (Ghanem et al., 2003) and was generously provided by the laboratory of Dr. Marc Ekker. The $s c n 1 / a b^{s 552}$ line has been previously described (Schoonheim et al., 2010) and was generously provided by the laboratory of Dr. Herwig Baier. Zebrafish of the TL strain were obtained from the Zebrafish International Resource Center (ZIRC). The zebrafish room was maintained on a 14/10 h light/dark cycle, with lights-on at 9 A.M. and lights-off at 11 P.M. Fish system water conditions were maintained in the following ranges by automated feedback controls: $29-30^{\circ} \mathrm{C}, \mathrm{pH} 7.5-8.0$, conductivity $(\mathrm{EC})$ $690-710$. Zebrafish embryos and larvae were raised in an incubator maintained at $28.5^{\circ} \mathrm{C}$, on the same light-dark cycle as the fish facility. At $5 \mathrm{dpf}$, zebrafish have not yet experienced sexual differentiation (Liew and Orbán, 

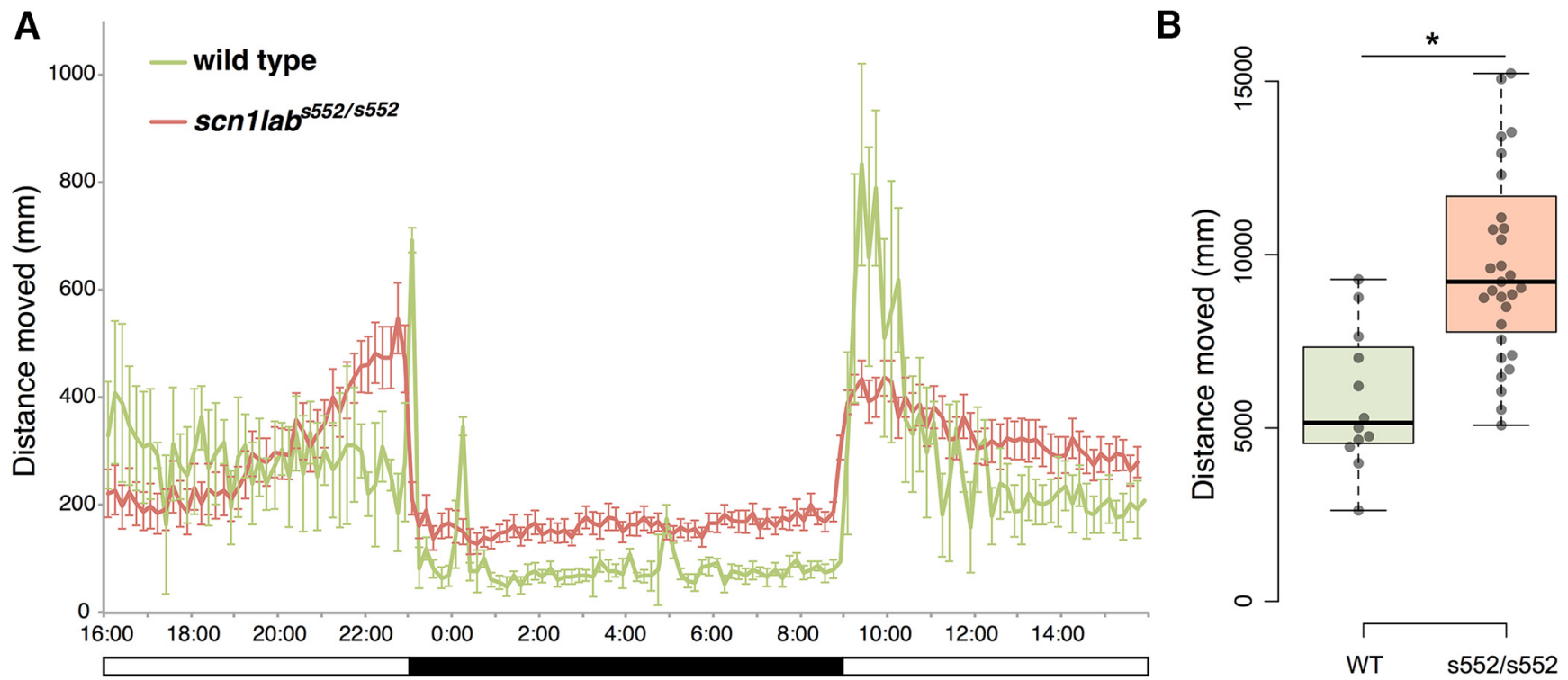

Figure 1. Mutant scn1lab ${ }^{5552}$ larvae had statistically significantly more locomotor activity at night compared to wild-type (WT) siblings. Larval zebrafish (5 dpf) were placed in individual wells of a flat-bottom 96-well plate and acclimated to the recording chamber. Twenty-four hours of movement data were collected beginning at 4 P.M. A, Data shown are sums of $10-\mathrm{min}$ bins \pm SD $(N=12$ WT, 31 Mut). The dark bar at the bottom indicates the 10-h period when lights were turned off, 11 P.M. to 9 A.M. B, Total nighttime distance moved by WT and homozygous mutant (s552/s552) larvae. Boxplot shows median, quartiles, and whiskers extending to the furthest point within 1.5 IQR (dot plots are shown, with outliers excluded). $* p<0.05$.

2014). Water used for embryos and larvae ("embryo medium") was made by adding $0.03 \%$ Instant Ocean and $0.000002 \%$ methylene blue to reverse-osmosis distilled water. Embryos and larvae were raised in plastic Petri dishes (90 $\mathrm{mm}$ in diameter, $20 \mathrm{~mm}$ in depth) and their housing density was limited to $\sim 60$ individuals per dish.

\section{Pharmacology}

The following drugs were dissolved in dimethylsulfoxide (DMSO, Sigma-Aldrich) to $10 \mathrm{mM}$ as stock solutions, and stored at $-20^{\circ} \mathrm{C}$ until needed: caffeine (Sigma), clemizole-HCl (Tocris), diazepam (Sigma-Aldrich), trazodone- $\mathrm{HCl}$ (Sigma-Aldrich), and valproic acid sodium salt (Sigma-Aldrich).

\section{Behavioral phenotyping, diurnal activity}

To monitor diurnal activity patterns, scn1lab ${ }^{5552 / s 552}$ larvae were placed individually in wells of a flat-bottom 96-well Falcon culture dish (BD Biosciences) and movement was tracked continuously during a $24-\mathrm{h}$ period, which included $14 \mathrm{~h}$ light-on and $10 \mathrm{~h}$ light-off phases. Each well contained $\sim 200 \mu \mathrm{l}$ of embryo medium. Behavior was monitored at room temperature $\left(21-22^{\circ} \mathrm{C}\right)$ using two DanioVision systems and EthoVision XT locomotion tracking software version (Noldus). The older system with EthoVision XT 8 software was used for initial experiments (Fig. 1). The newer system with EthoVision XT 11 software was used for all other experiments. Total distance moved measurements were consistent within systems, but not comparable between systems as the software detection parameters and image quality are not identical on the two systems; 5-dpf larvae were allowed to acclimate to the tracking arena for 3-4 h, and then $24 \mathrm{~h}$ of continuous behavioral data were recorded beginning at 4 P.M. The light-dark cycle continued as usual: lights-off occurred at 11 P.M. and lights-on at 9 A.M.

\section{Behavioral phenotyping, open field}

Open field behavior was examined in wells of a six-well plate, each containing $6 \mathrm{ml}$ of egg water; 5 -dpf zebrafish larvae were placed individually in separate wells, using a glass Pasteur pipette. Larvae are initially placed near the center of the arena, but tend to shift slightly as the plate is transferred into the recording apparatus. Using EthoVision, 5 min of tracking data were immediately recorded with no acclimation period. The video data were analyzed in 30-s time bins. For each group, we calculated distance traveled and time spent in the center zone (diameter = $25.5 \mathrm{~mm}$ ) of the well (inner diameter $=36.6 \mathrm{~mm}$ ).

For drug treatment trials, drugs in DMSO were diluted in embryo medium to a final concentration of $250 \mu \mathrm{M}, 25$ $\mu \mathrm{M}$, or $2.5 \mu \mathrm{M}$, as described (with 2.5\% DMSO). Zebrafish larvae were incubated in embryo medium containing the drug or DMSO for 30 min before transfer to the open field (in groups of three fish in $2 \mathrm{ml}$ of solution in a well of a 24-well plate). Individual larvae were then transferred to a single well of a six-well plate containing DMSO $(2.5 \%)$ or drug dissolved in DMSO, for the duration of the assay.

\section{Cell count}

For imaging of interneurons, we in-crossed scn1/ab ${ }^{5552 /+}$; $\operatorname{Tg}(1.4 d l \times 5 a-d l \times 6 a: G F P)$ adult zebrafish. Green fluorescent protein (GFP)-expressing larvae were raised in PTU and imaged at $5 \mathrm{dpf}$ using a Zeiss Z.1 light sheet microscope with $20 \times$ objective. The sample chamber was filled with embryo medium. Zebrafish larvae were anesthetized in $0.04 \%$ tricaine mesylate for $10 \mathrm{~min}$, then embedded in $2 \%$ 
low melting point agarose inside a glass capillary. Image stacks were taken extending from the first dorsal GFPpositive neuron, at intervals of $4.94 \mu \mathrm{m}$ with 20 slices per fish. Imaging files were coded and analyzed post hoc by an investigator blind to phenotype and genotype. Following imaging, the fish were removed from agar and genotyped.

FIJl software was used for analysis of image stacks (Schindelin et al., 2012). Cells were counted automatically using 3D Objects Counter.

\section{Genotyping}

For genotyping, we extracted genomic DNA (gDNA) from whole larvae using the Zebrafish Quick Genotyping DNA Preparation kit (Bioland Scientific). We amplified scn1lab gDNA using GoTaq Green Master Mix (Promega) and the following primers: scn1lab-F, AAATCTCTCTGTTAGACAGAAATTGGGG and scn1lab-R, TTGCTCAGGCTGTGTGATGAGG. These primers amplify a 314-bp region, including the scn1lab mutation site. The mutant allele was then detected by digestion of the amplicon with Acul, for which a restriction site is introduced in the mutant, and electrophoresis to separate the digested samples on a $1 \%$ agarose gel.

\section{Statistics and graphing}

JASP version 0.8.0.1 software was used for statistical tests (https://jasp-stats.org/). Microsoft Excel, R software ( $\mathrm{R}$ Core Team, 2016) and the beeswarm package were used for plotting data.

\section{Results}

Diurnal locomotor activity is altered in mutant larvae

To assess diurnal movements indicative of sleep/wake cycles, we tracked larvae from scn1/ab ${ }^{\mathrm{s5} 52 /+}$ in-crosses continuously during a 24-h light/dark period (Zhdanova et al., 2001; Yokogawa et al., 2007; Rihel et al., 2010; Elbaz et al., 2013). To quantify disruptions to sleep activity, total distance moved during the dark (sleep) period was compared between groups. Distance moved at night (11 P.M. to 9 A.M.) showed statistically significant differences between genotypes: scn1/ab $b^{5552 / s 552}$ traveled a greater distance compared to wild-type siblings (Fig. 1B). Welch's $t$ test showed a difference between genotypes (mean \pm SEM, measured in $\mathrm{mm}$ ): wild type, $5622.7 \pm$ $1181.5(N=12)$; homozygous $10,084.0 \pm 1244.8(N=$ $31) ; t_{(39.87)}=4.410, p<0.001$. These differences in diurnal activity patterns suggest that $s c n 1 / a b^{5552 / s 552}$ larvae exhibit sleep and diurnal rhythm disturbances.

In the final hour before lights-off (10-11 P.M.), scn1/ab ${ }^{5552 / s 552}$ mutant larvae traveled a greater distance $(2900 \pm 327.5)$ compared to wild-type siblings (1490 \pm $\left.339.3 ; t_{(31.14)}=2.989 ; p=0.005\right)$. We observed trends toward increased activity by the mutants in the first hour of tracking (4-5 P.M.; mutant, $1264 \pm 227.8$; wild type, $\left.2090 \pm 600.3 ; t_{(14.29)}=1.289, p=0.218\right)$, and the first hour after lights-on (9-10 A.M.; mutant, $2341 \pm 162.0$; wild type, $\left.3715 \pm 800.5 ; t_{(11.91)}=1.683, p=0.118\right)$, but these did not reach statistical significance.

\section{Sleep pharmacology}

To determine if the observed disruptions of diurnal rhythms could be pharmacologically alleviated, drug trials were conducted on scn1lab ${ }^{\mathrm{s5} 52 / 5552}$ larvae during a full 24-h period. We found that drug treatments could significantly decrease nighttime locomotor patterns indicative of wakefulness. We tested two drug concentrations based on previous reports (Herrmann, 1993; Zhdanova et al., 2001; Richendrfer et al., 2012; Baraban et al., 2013; Koseki et al., 2014) and pilot experiments; a "low" concentration of $2.5 \mu \mathrm{M}$ and a "high" concentration of $25 \mu \mathrm{M}$ for four compounds: valproic acid, diazepam, trazodone, and clemizole (Fig. 2).

At $2.5 \mu \mathrm{M}$ concentration (Fig. 2B), $t$ tests showed no difference between DMSO and valproic acid, trazodone, diazepam, or clemizole (Table 1). At $25 \mu \mathrm{M}$ concentration (Fig. 2D), $t$ tests showed no difference between DMSO and valproic acid or trazodone. On the other hand, $t$ tests revealed that two drug treatments led to less distance traveled compared to DMSO: diazepam and clemizole (Table 1).

\section{Open field deficits in mutant larvae}

To study anxiety-like and locomotor behavior in more detail, we adapted a version of the open field test (Walsh and Cummins, 1976). This assay is designed to give temporal as well as spatial resolution regarding position and movement over time after larvae are introduced to a novel cylindrical chamber. Single larvae were placed in individual wells of a flat-bottom six-well plate and movement was tracked during a 5-min recording epoch. DMSO (2.5\%) was tested for effects on larval behavior compared to embryo medium using Welch's $t$ test ( $N=6$ per group). No significant effects were found for total duration in center (mean \pm SEM): water, $87.9 \pm 44.7$; DMSO, $116.6 \pm 45.2$ $\left(t_{(10.0)}=0.451, p=0.662\right.$ ) or total distance moved (mean \pm SEM, measured in $\mathrm{mm}$ ): water, $869.8 \pm 69.8$; DMSO, $815.2 \pm 36.0\left(t_{(7.49)}=0.695, p=0.508\right)$, or any of the individual time bins.

Representative tracking plots for six larvae per genotype are shown in Figure 3. In this assay, scn1lab ${ }^{5552 / s 552}$ mutant larvae have significantly impaired (low) distance moved compared to wild-type control sibling larvae. Total distance moved (Fig. 3B) was different between genotypes (mean \pm SEM, measured in $\mathrm{mm}$ ): wild type, $5622.7 \pm$ $1181.5(N=33)$; homozygous, $10,084.0 \pm 1244.8(N=18)$ by Welch's $t$ test $\left(t_{(48.43)}=7.256, p<0.001\right)$. For time spent in the center zone $(25.5 \mathrm{~mm})$ of the arena $(36.6 \mathrm{~mm})$, homozygous scn1lab $b^{5552 / s 552}$ mutants were significantly reduced compared to wild-type siblings. Duration in center (Fig. 3C) was also different between wild-type and homozygous mutants (mean \pm SEM): wild type, $158.2 \pm$ $11.6(N=33)$; homozygous, $81.7 \pm 18.1(N=18)$ by Welch's $t$ test $\left(t_{(31.11)}=3.552, p=0.001\right)$.

\section{Open field pharmacology}

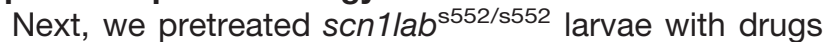
and assessed effects using the open field assay. All drugs (valproic acid, diazepam, trazodone, and clemizole) were tested at two different concentrations, $25 \mu \mathrm{M}$ and 250 $\mu \mathrm{M}$. The $25 \mu \mathrm{M}$ concentration of each drug had no sig- 

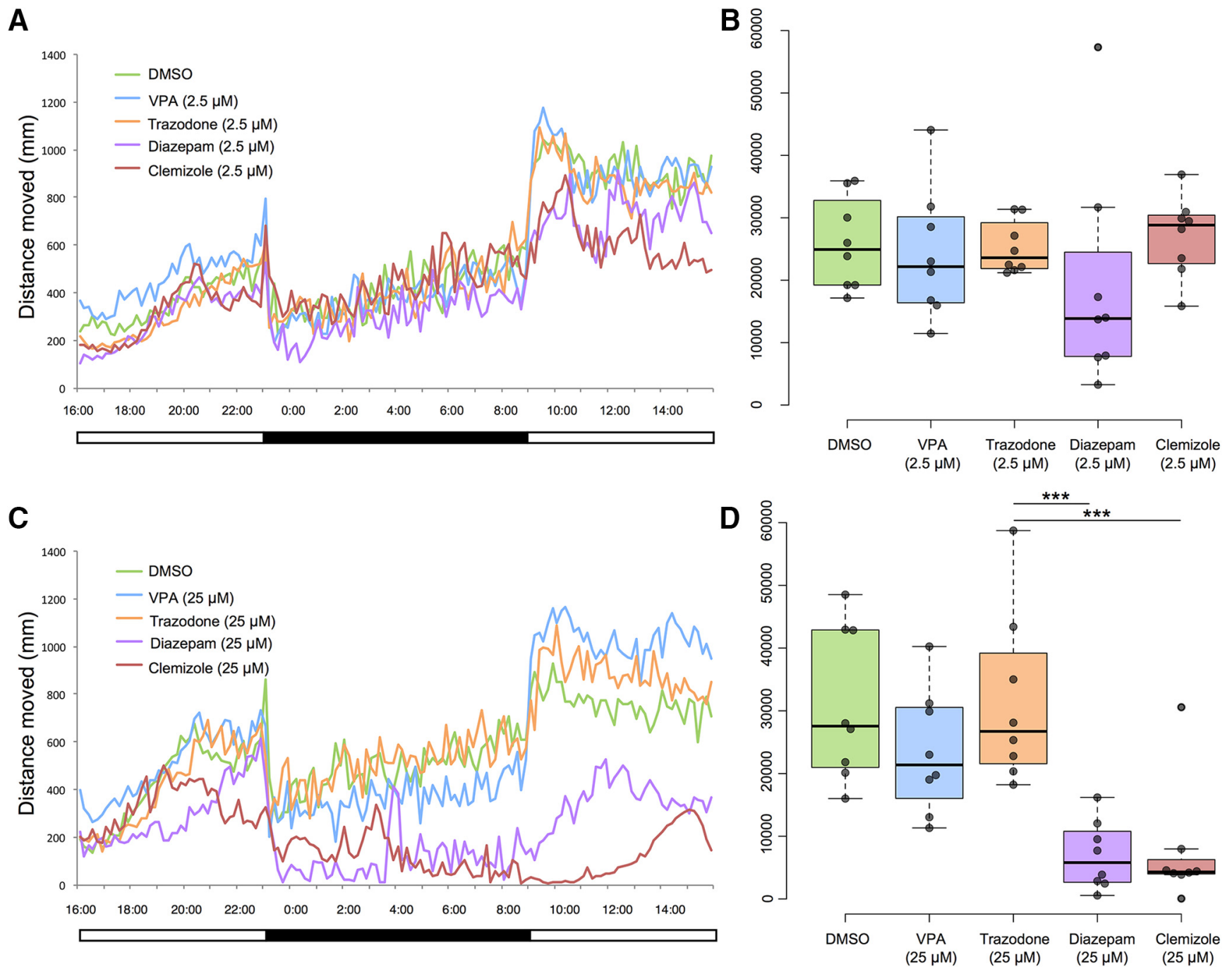

Figure 2. Full 24-h light-dark cycle behavioral data reveal effects of treatment with $2.5 \mu \mathrm{M}(\boldsymbol{A}, \boldsymbol{B})$ and $25 \mu \mathrm{M}(\boldsymbol{C}, \boldsymbol{D})$ concentrations of drugs in DMSO. Both diazepam and clemizole, at $25 \mu \mathrm{M}$ concentration, significantly decreased distance moved at night compared to vehicle (DMSO)-treated control. Mean values $(N=8$ individuals per group) per 10 -min time bin are shown at left $(\boldsymbol{A}, \boldsymbol{C})$. Total night-time distances moved (during $10 \mathrm{~h}$ of darkness), are shown at right $(\boldsymbol{B}, \boldsymbol{D})$. Boxplot shows median, quartiles, and whiskers extending to the furthest point within 1.5 IQR (dot plots are shown, with outliers excluded). The $2.5 \mu \mathrm{M}$ concentration of each drug had no significant effect on total nighttime locomotor activity, an indicator of wakefulness $(\boldsymbol{B})$. On the other hand, the $25 \mu \mathrm{M}$ treatment with either diazepam or clemizole significantly reduced the nighttime locomotor activity $(\boldsymbol{D})$. $* * * p<0.001$.

nificant effect on either time spent in the center or total movement (Fig. 4). No effect was observed after treatment of zebrafish larvae with $25 \mu \mathrm{M}$ valproic acid, diazepam, trazodone, or clemizole on distance moved or duration spent in the center of the arena in an open field test $(N=$ 18 per group). All drug treatments were compared to DMSO vehicle using Welch's $t$ test (Table 2).

On the other hand, the $250 \mu \mathrm{M}$ concentration of either diazepam or clemizole, the same two drugs with significant effects in our sleep assay (Fig. 2), significantly reduced the overall locomotor activity we observed while increasing the duration spent in the center of the arena, a measure of low-anxiety exploratory behavior (Fig. 4). All drug treatments were compared to DMSO vehicle using Welch's $t$ test. Valproic acid and trazodone had no significant effect on distance moved or duration in center (Fig.
$4 A-D$ ). Diazepam and clemizole decreased distance moved and increased duration in center (Fig. 4E-H).

The effects of clemizole and diazepam, which significantly modified open field behavior in scn1lab ${ }^{5552 / s 552}$ larvae, were also tested further in wild-type larvae of the TL strain (Fig. 5). Clemizole and diazepam were compared to DMSO in the same experiment ( $N=18$ per group).

For total distance traveled during the 5-min assay, clemizole $(153.3 \pm 17.84)$ and diazepam (10.25 \pm 2.76$)$, led to significant reductions compared to the control DMSO-treated larvae $(529.0 \pm 88.26)$, using Welch's $t$ test (clemizole: $t_{(18.39)}=4.172, p<0.001$; diazepam: $t_{(17.03)}=$ 5.875, $p<0.001)$. In TL larvae, we found no significant effects of either clemizole $(117.0 \pm 20.45)$ or diazepam $(136.1 \pm 35.4)$ on total duration in center measured in $\mathrm{mm}$, compared to DMSO $(89.1 \pm 19.1)$, using Welch's $t$ test 
Table 1. Night phase movement statistical data

\begin{tabular}{|c|c|c|c|c|c|c|}
\hline $\begin{array}{l}\text { Drug } \\
(2.5 \mu \mathrm{M})\end{array}$ & Mean \pm SEM & Student's $t$ & df & $p$ & Levene's $p$ & Shapiro-Wilk $p$ \\
\hline DMSO control & $25,868.7 \pm 2606.4$ & & & & & 0.308 \\
\hline Valproic acid & $24,120.2 \pm 3697.7$ & 0.386 & 14 & 0.705 & 0.432 & 0.651 \\
\hline Trazodone & $25,239 \pm 1494.6$ & 0.209 & 14 & 0.837 & 0.109 & 0.068 \\
\hline Diazepam & $19,108.0 \pm 6247.0$ & 0.999 & 14 & 0.335 & 0.133 & 0.034 \\
\hline $\begin{array}{l}\text { Clemizole } \\
(25 \mu \mathrm{M})\end{array}$ & $27,076.0 \pm 2289.8$ & 0.348 & 14 & 0.733 & 0.594 & 0.863 \\
\hline DMSO control & $(30,921.1 \pm 4311.6)$ & & & & & 0.293 \\
\hline Valproic acid & $23,435.8 \pm 3465.6$ & 1.353 & 14 & 0.197 & 0.324 & 0.75 \\
\hline Trazodone & $31,490.0 \pm 4857.9$ & 0.088 & 14 & 0.931 & 0.932 & 0.188 \\
\hline Diazepam & $6908.1 \pm 1916.6$ & 5.089 & 14 & $<0.001$ & 0.01 & 0.567 \\
\hline Clemizole & $7475.7 \pm 3384.2$ & 4.278 & 14 & $<0.001$ & 0.171 & $<0.001$ \\
\hline
\end{tabular}

Larval zebrafish ( $N=18$ per group) were video recorded during the 10-h night phase and total distance was measured for larva treated with DMSO or with one of four drugs at two concentrations (see Materials and Methods). For DMSO and each drug tested, the table shows distance moved in mm (mean \pm $\mathrm{SEM}), t$ value, degrees of freedom, and $p$ value (see Results). Data from lower concentration tested (2.5 $\mu \mathrm{M})$ is shown at top; $25 \mu \mathrm{M}$ is shown below.

(clemizole: $t_{(33.9)}=0.999, p=0.325$; diazepam: $t_{(26.2)}=$ $1.169, p=0.253)$.

To further characterize the effects of pharmacological interventions in our open field assay, we tested the effect of caffeine at a concentration of $250 \mu \mathrm{M}$ (Maximino et al., 2011), using the same protocol as applied for the other drugs. Caffeine-treated wild-type larvae moved significantly less (mean \pm SEM, measured in mm; $333.4 \pm$ 56.23) than DMSO-treated controls $\left(562.5 \pm 105.0 ; t_{(32)}=\right.$ 2.103, $p<0.043$ ), but did not significantly differ in duration spent in the center of the arena $\left(t_{(32)}=0.679, p<\right.$ $0.465)$. In the mutant larvae, we observed no significant effects of caffeine on either total distance traveled $\left(t_{(37)}=\right.$ $1.428, p<0.162)$ or duration spent in the center of the arena $\left(t_{(37)}=0.425, p=0.673\right)$.

\section{Interneuron density}

Because mutations in mammalian Scn1a, which is expressed in inhibitory interneurons, impair interneuron firing activity (Yu et al., 2006; Mistry et al., 2014), we examined interneuron numbers at $5 \mathrm{dpf}$. To visualize interneurons scn 1/abs552/s552 were crossed with a zebrafish line expressing a transgene with GFP flanked by both a $3.5-\mathrm{kb}$ fragment of the dlx6 promoter and a 1.4-kb fragment of the $d / x 5 / 6$ intergenic region (Ghanem et al., 2003). This reporter line labels distinct populations of interneurons (Robles et al., 2011). To evaluate interneuron density we conducted live light-sheet microscopy of scn1/ab ${ }^{\text {s552/s552. }}$ Tg(1.4dlx5a-dlx6a:GFP) larvae (Fig. 6). Live imaging revealed cells labeled by GFP in the telencephalon, optic tectum, cerebellum, and diencephalon. In an imaging stack centered on the optic tectum, we counted GFP-positive cells for $s c n 1 / a b^{s 552 / s 552}$ and sibling larvae. Welch's $t$ test was used to test for differences between genotypes (mean \pm SEM): wild type, $144.9 \pm 11.7(N=8)$; homozygous, $135.7 \pm 17.5$ $(N=12)$. No statistically significant effect of genotype was found $\left(t_{(17.99)}=0.406, p=0.690\right)$.

\section{Discussion}

Behavioral deficits greatly decrease quality of life for DS patients. Our findings here demonstrate that zebrafish provide useful models of behavioral as well as neurophysiological symptoms of epileptic encephalopathies such as
DS. While Scn1a haploinsufficiency is known to cause sleep and circadian abnormalities, hyperactivity, autisticand anxiety-like behavior in mouse models, these comorbidities have not been previously investigated in a systematic way in scn1lab mutant zebrafish. The significant behavioral differences from wild-type larvae, as demonstrated here, and their sensitivity to pharmacological treatments, expand the repertoire of assays that can be used to characterize zebrafish models for neurologic disease and uncover new treatments.

\section{Sleep}

Evidence from patients, mice, and zebrafish suggest that SCN1A homologs play a conserved role in regulating motor activity and daily patterns of locomotion. Zebrafish, including larvae, are diurnal in laboratory conditions, with a light-entrainable circadian clock (Cahill et al., 1998). Wild-type larvae exhibit hallmarks of sleep, including immobility, increased arousal threshold that can rapidly be reversed, characteristic posture, and sleep rebound following deprivation (Zhdanova et al., 2001). Sleep in zebrafish can be quantified as bouts of immobility at night (Elbaz et al., 2013). Our assay simplifies this approach to measure activity levels in day and night without specifying the microstructure of rest bouts. We found disrupted levels of locomotor activity at several points throughout the light-dark cycle, with a consistently increased activity

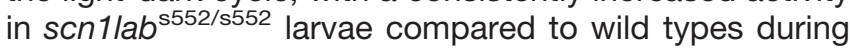
the dark phase. Like humans, and in contrast to mice, zebrafish sleep at night, making them a useful model for diurnal behavioral patterns. High levels of cycling alternating pattern activity in non-REM sleep were reported in DS patients (Dhamija et al., 2014). Scn1a ${ }^{+/-}$mice similarly exhibit disrupted circadian activity patterns compared to controls, with decreased activity in the active (dark) phase and increased activity in the rest (light) phase (Han et al., 2012a). Mice with a heterozygous knockin missense Scn1a mutation showed increased wakefulness in the active (dark) phase (Papale et al., 2013). Taken together, data from zebrafish and mouse models suggest that diurnal behavioral deficits associated with mutations in SCN1A homologs may be an important and conserved feature of SCN1A deficiency. 
A

wild

type
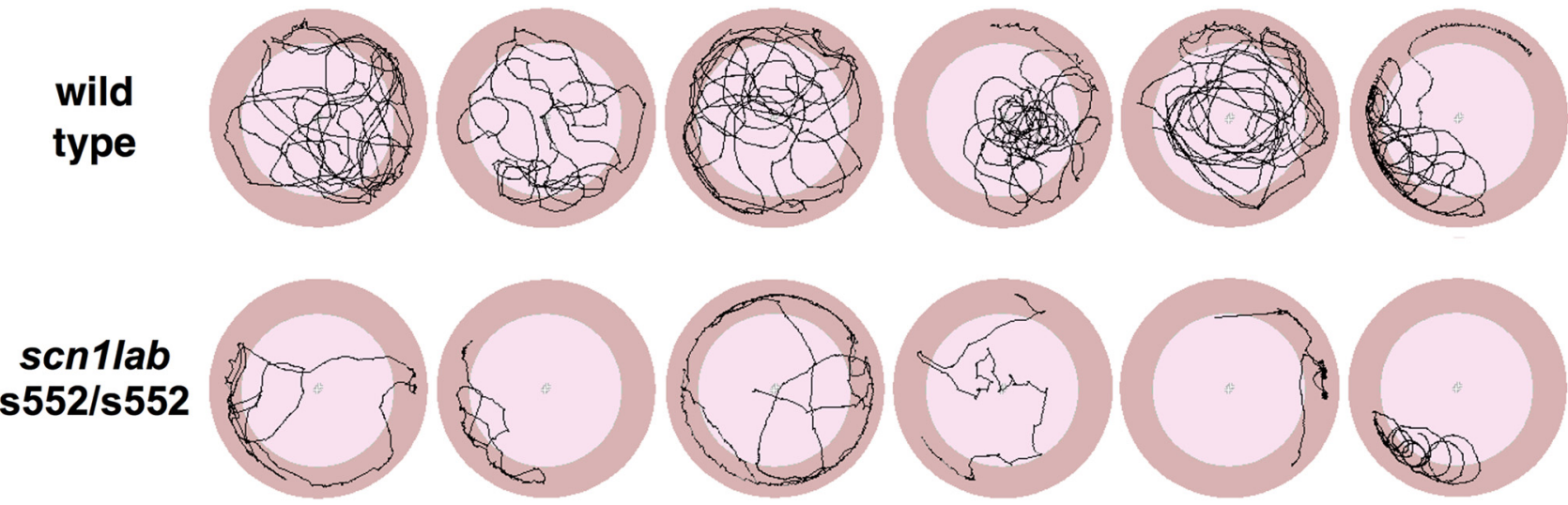

B
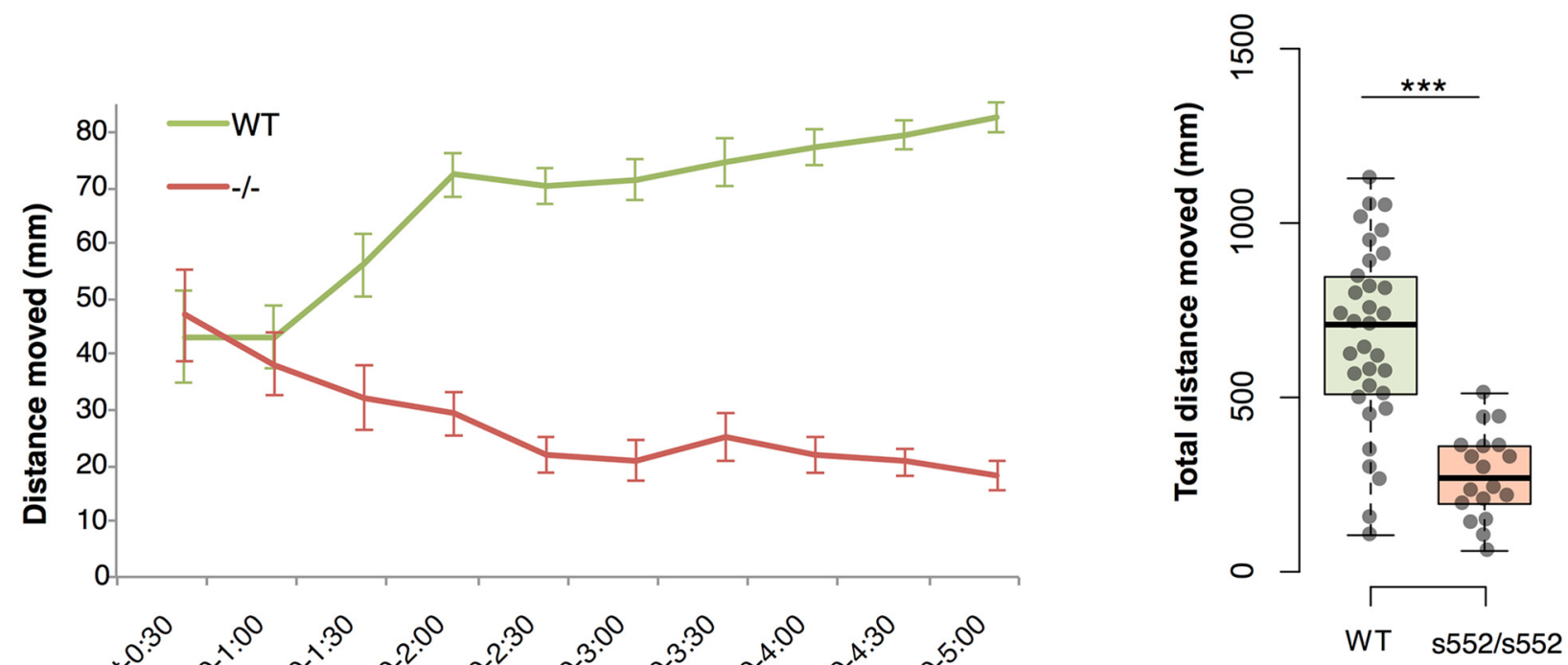

C
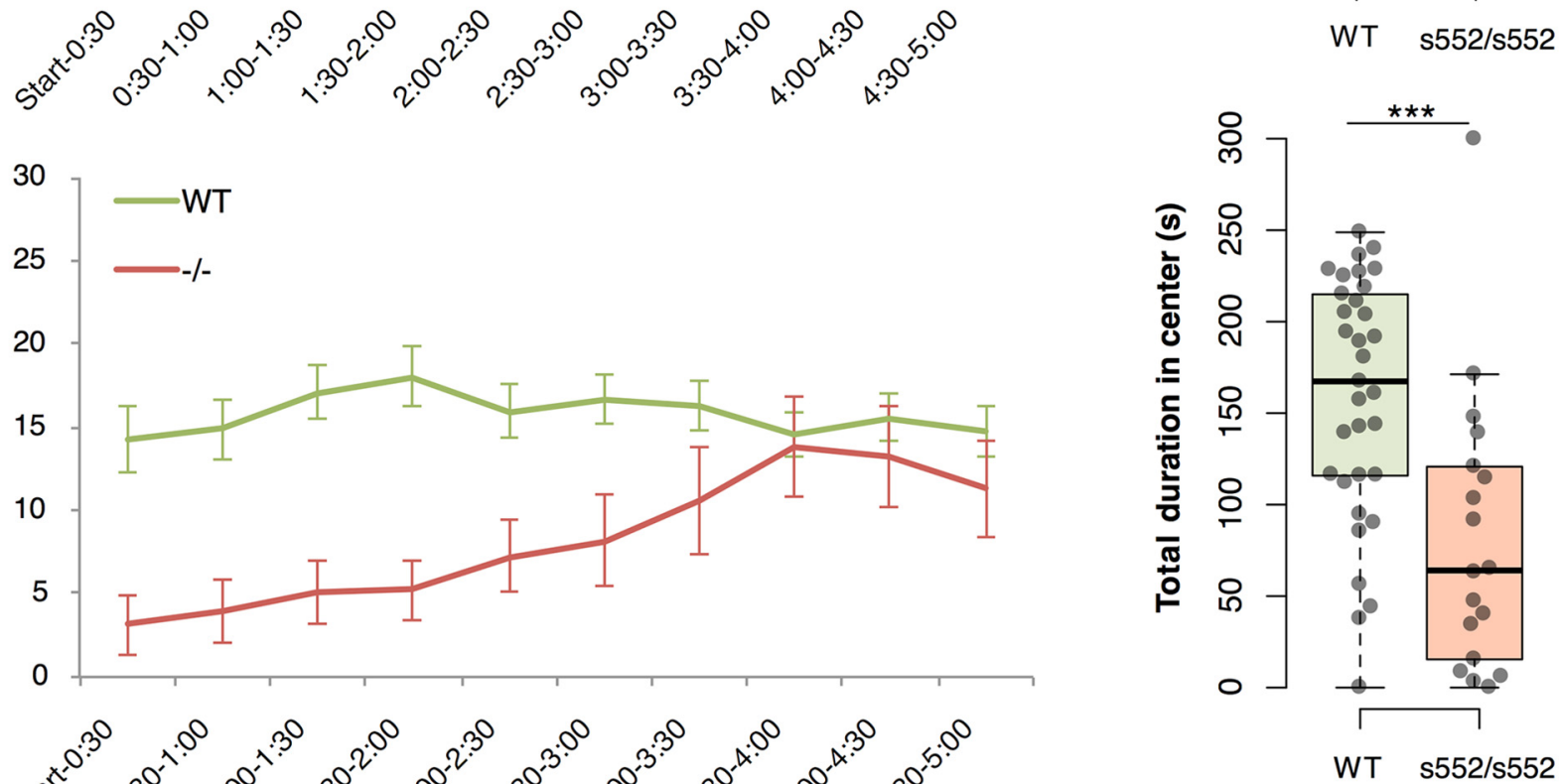

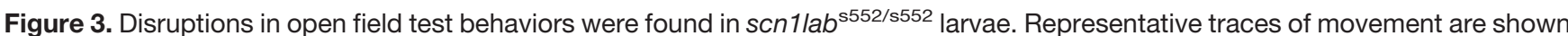
(A). Mutant scn 1/ab ${ }^{5552 / s 552}$ larvae initially have normal levels of overall movement (B) but spend less time than controls in the center of the arena $(\boldsymbol{C})$. At subsequent time points, scn1/ab ${ }^{\mathrm{s552/s552}}$ larvae's movement decreases $(\boldsymbol{B})$ and their time spent in the center of the arena increases $(\boldsymbol{C})$. Time bins are $30 \mathrm{~s}$, bars show SEM. On the right, dot plots are shown with boxplot indicating median, quartiles, and whiskers extending to the furthest point within 1.5 IQR; statistical analyses were conducted on these totals. $* * * p<0.001$. 
A

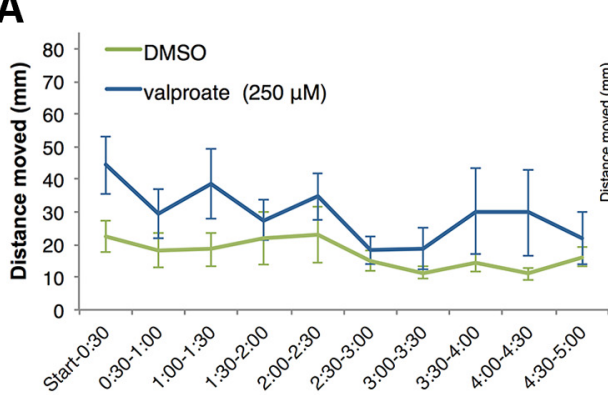

C

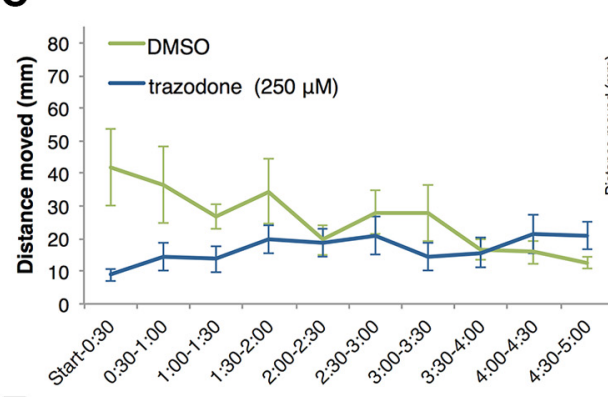

E

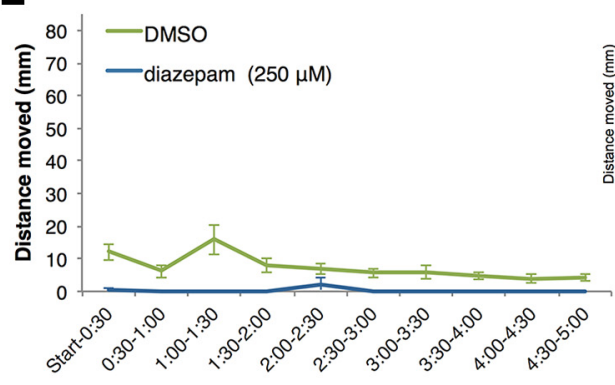

G
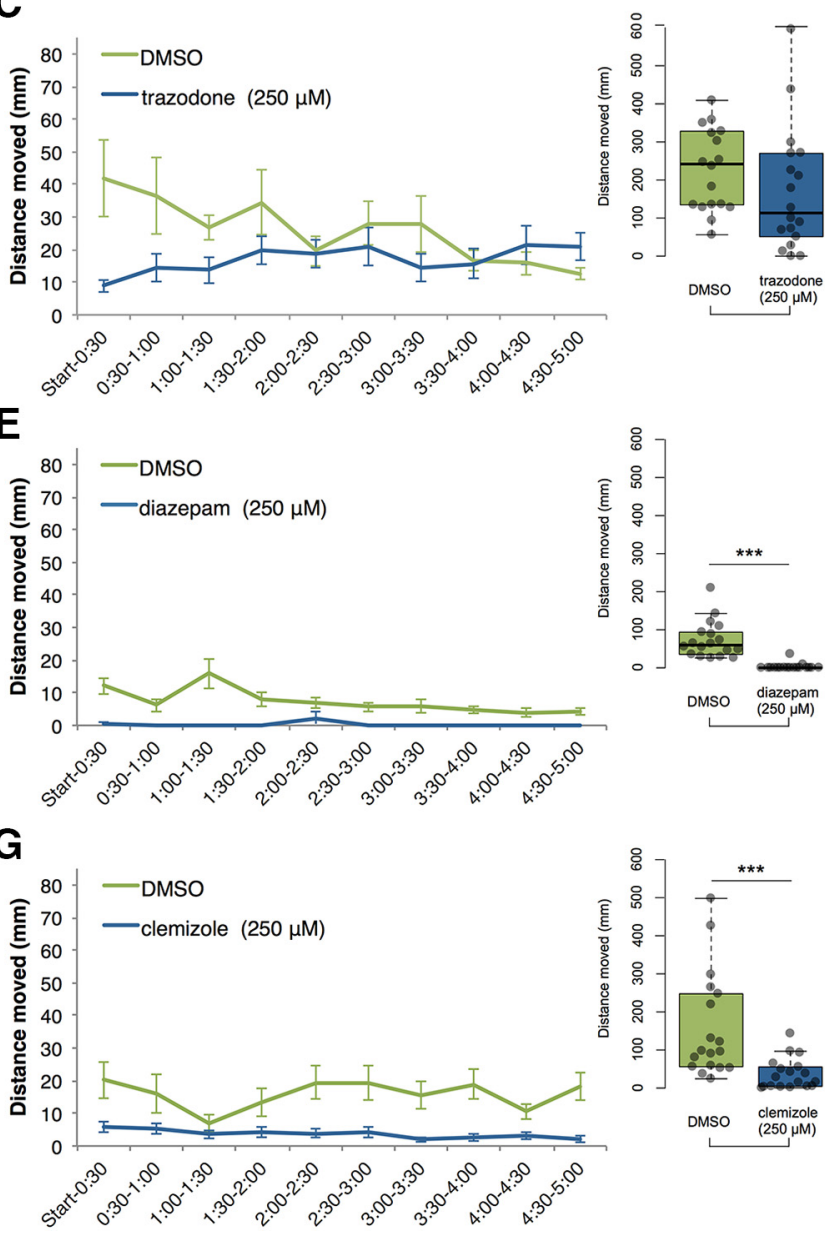

B

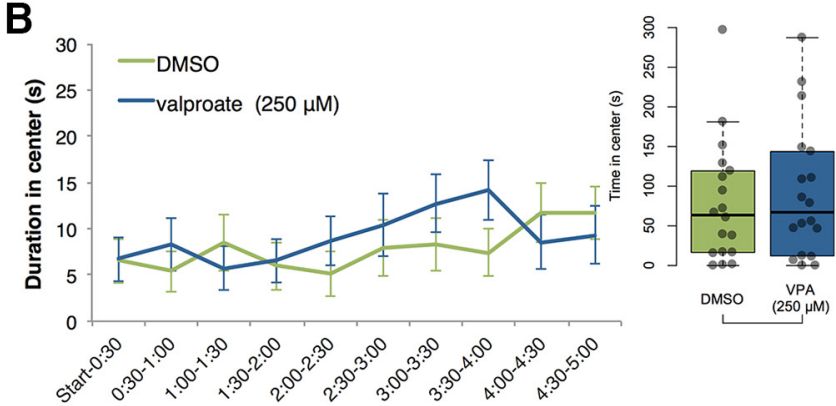

D

$\mathbf{F}$
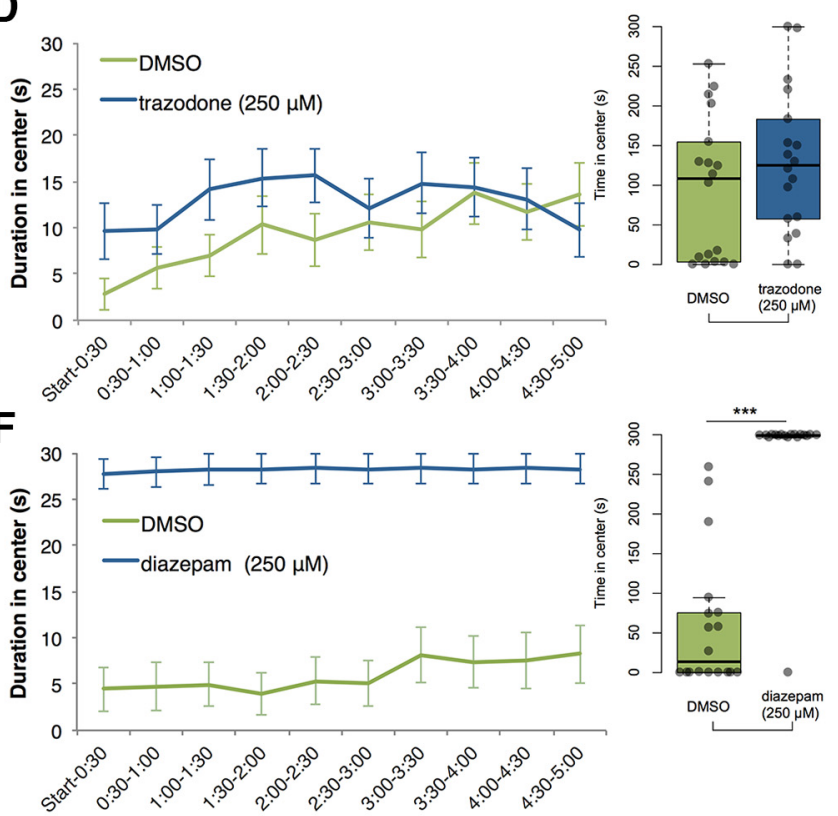

H

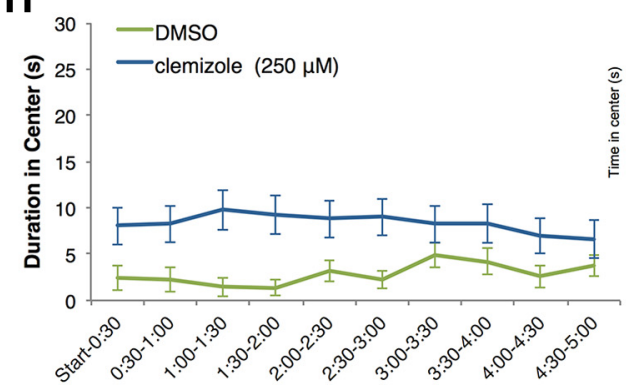

Figure 4. Treatment with antiepileptic drugs at $250 \mu \mathrm{M}$. Statistically significant decreases in locomotion (distance traveled) and duration in the center of the open field were observed after treatment of zebrafish larvae with $250 \mu \mathrm{M}$ diazepam $(\boldsymbol{C}, \boldsymbol{D})$ or clemizole $(\boldsymbol{G}, \boldsymbol{H})$, but not after treatment with valproic acid $(\boldsymbol{A}, \boldsymbol{B})$ or trazodone $(\boldsymbol{E}, \boldsymbol{F} ; \boldsymbol{N}=18$ per group). Data are plotted in 30 -s time bins showing mean \pm SEM (left), and the 5-min total for each all individuals, are plotted on the right. $* * * p<0.001$.

The increased movement that we observed in scn1lab ${ }^{5552 / s 552}$ larvae during the dark phase (night) may correspond directly to the greater electrical signals that were detected during the dark phase using a recently developed microfluidic multielectrode recording chamber method (Hong et al., 2016). Further development and characterization of zebrafish models of epileptic encephalopathies could reveal important mechanistic insights related to sleep. Future in vivo imaging and electrophysiology may also contribute to our understanding of neural activity patterns during the course of waking and sleeping (Wang et al., 2011).

\section{Open field exploration}

Our open field assay featured high temporal resolution and revealed severe deficits in open field exploration and movement. Exploration in an open field assay was similarly disrupted in a zebrafish mecp2 mutant model for Rett syndrome (Pietri et al., 2013). Key features of our assay include the use of six-well plates with 36.6- $\mathrm{mm}$ diameter wells, pretreatment with drug for $30 \mathrm{~min}$ followed by continuous drug exposure, and immediate recording of locomotion following addition of the larvae to the novel wells. Binning the data into $30-\mathrm{s}$ time bins revealed pre- 
Table 2. Open field test statistical data

\begin{tabular}{|c|c|c|c|c|c|c|}
\hline $\begin{array}{l}\text { Drug } \\
(25 \mu \mathrm{M})\end{array}$ & Measurement & Treated & DMSO control & Welch's $t$ & $d f$ & $p$ \\
\hline \multirow[t]{2}{*}{ VPA } & Distance $(\mathrm{mm})$ & $287.6 \pm 37.31$ & $234.2 \pm 29.23$ & 1.127 & 32.16 & 0.268 \\
\hline & Center duration (s) & $91.93 \pm 16.54$ & $64.51 \pm 17.93$ & 1.124 & 33.78 & 0.269 \\
\hline \multirow[t]{2}{*}{ Trazodone } & Distance $(\mathrm{mm})$ & $199.9 \pm 29.26$ & $198.0 \pm 17.79$ & 0.055 & 28.05 & 0.956 \\
\hline & Center duration (s) & $72.81 \pm 21.17$ & $85.73 \pm 19.31$ & 0.451 & 33.72 & 0.655 \\
\hline \multirow[t]{2}{*}{ Diazepam } & Distance $(\mathrm{mm})$ & $138.5 \pm 28.87$ & $175.6 \pm 26.73$ & 0.941 & 33.8 & 0.354 \\
\hline & Center duration (s) & $73.25 \pm 18.55$ & $66.49 \pm 18.03$ & 0.261 & 33.97 & 0.796 \\
\hline \multirow[t]{2}{*}{ Clemizole } & Distance $(\mathrm{mm})$ & $177.9 \pm 32.12$ & $107.5 \pm 15.12$ & 1.983 & 24.18 & 0.059 \\
\hline & \multicolumn{6}{|c|}{$(250 \mu \mathrm{M})$} \\
\hline \multirow[t]{2}{*}{ VPA } & Distance $(\mathrm{mm})$ & $293.6 \pm 52.82$ & $172.2 \pm 26.99$ & 2.047 & 25.31 & 0.051 \\
\hline & Center duration (s) & $91.07 \pm 20.05$ & $78.36 \pm 18.31$ & 0.468 & 33.72 & 0.643 \\
\hline \multirow[t]{2}{*}{ Trazodone } & Distance $(\mathrm{mm})$ & $168.8 \pm 38.14$ & $260.1 \pm 43.95$ & 1.57 & 33.34 & 0.126 \\
\hline & Center duration (s) & $128.82 \pm 21.62$ & $93.96 \pm 21.30$ & 1.149 & 33.99 & 0.259 \\
\hline \multirow[t]{2}{*}{ Diazepam } & Distance $(\mathrm{mm})$ & $2.56 \pm 2.04$ & $73.06 \pm 11.40$ & 6.089 & 18.08 & $<0.001$ \\
\hline & Center duration (s) & $282.07 \pm 16.59$ & $59.73 \pm 20.15$ & 8.518 & 32.8 & $<0.001$ \\
\hline \multirow[t]{2}{*}{ Clemizole } & Distance $(\mathrm{mm})$ & $36.89 \pm 9.61$ & $158.38 \pm 32.62$ & 3.572 & 19.93 & 0.002 \\
\hline & Center duration (s) & $83.29 \pm 17.31$ & $28.31 \pm 6.61$ & 2.967 & 21.85 & 0.007 \\
\hline
\end{tabular}

Larval zebrafish ( $N=18$ per group) were pretreated one of four drugs at two concentrations (see Materials and Methods). Each treatment group was tested at the same time as a control group treated with DMSO. Drug-treated and control larvae were then placed in a novel arena and behavior was video recorded for $5 \mathrm{~min}$. Both distance moved $(\mathrm{mm})$ and duration spent in center of the arena $(\mathrm{s})$ were measured for all larva. Table shows distance moved in mm (mean \pm $\mathrm{SEM}), t$ value, degrees of freedom, and $p$ value. Data from lower concentration tested (25 $\mu \mathrm{M})$ is shown at top; $250 \mu \mathrm{M}$ is shown below.

viously unappreciated features of the scn $1 / a b^{\text {s552/s552 }} \mathrm{mu}-$ tant larvae behavior that could have been obscured with larger time bins, including a worsening (decreasing) trend in distance moved over the 5-min assay, accompanied by an improving (increasing) amount of time spent in the center of the arena. In contrast, no evidence was found for habituation in wild-type larvae in a larger $(9.6 \mathrm{~cm})$ dish over 15 min (using 5-min time bins; Ahmad and Richardson, 2013). Reduced overall level of movement appears to be the primary effect of clemizole and diazepam in wildtype and mutant larvae, leading to increased variability and differences in duration spent in the center of the
A

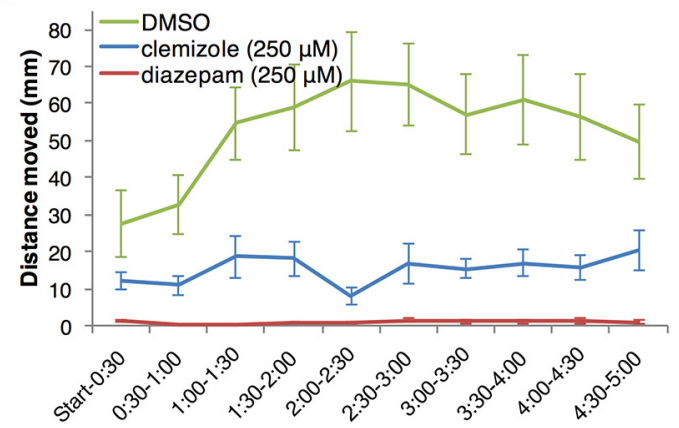

B

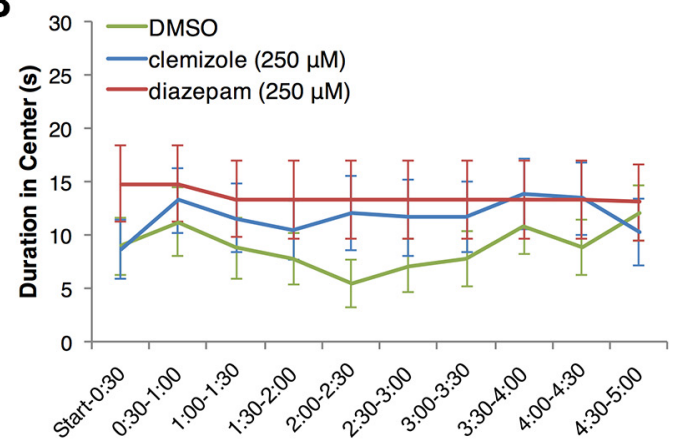

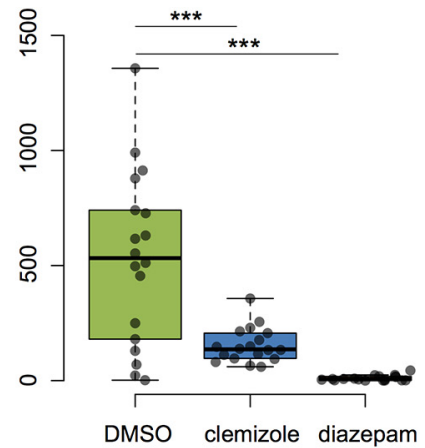

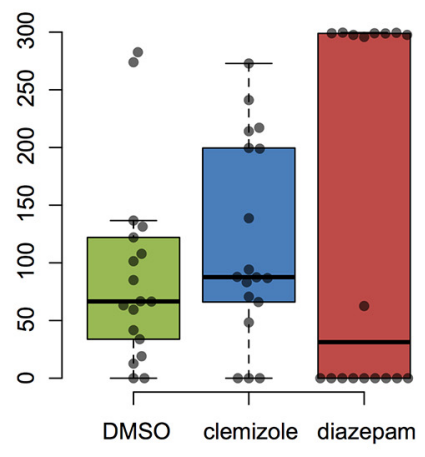

Figure 5. Wild-type TL zebrafish larvae open field behavior is modulated by clemizole and diazepam. Statistically significant decreases in distance traveled $(\boldsymbol{A})$ in open field test were observed after treatment of zebrafish larvae with $250 \mu \mathrm{M}$ clemizole or diazepam, compared to DMSO-treated controls. No statistically significant effects on duration spent in the center (B) were found for either clemizole or diazepam. $* * * p<0.001$. 

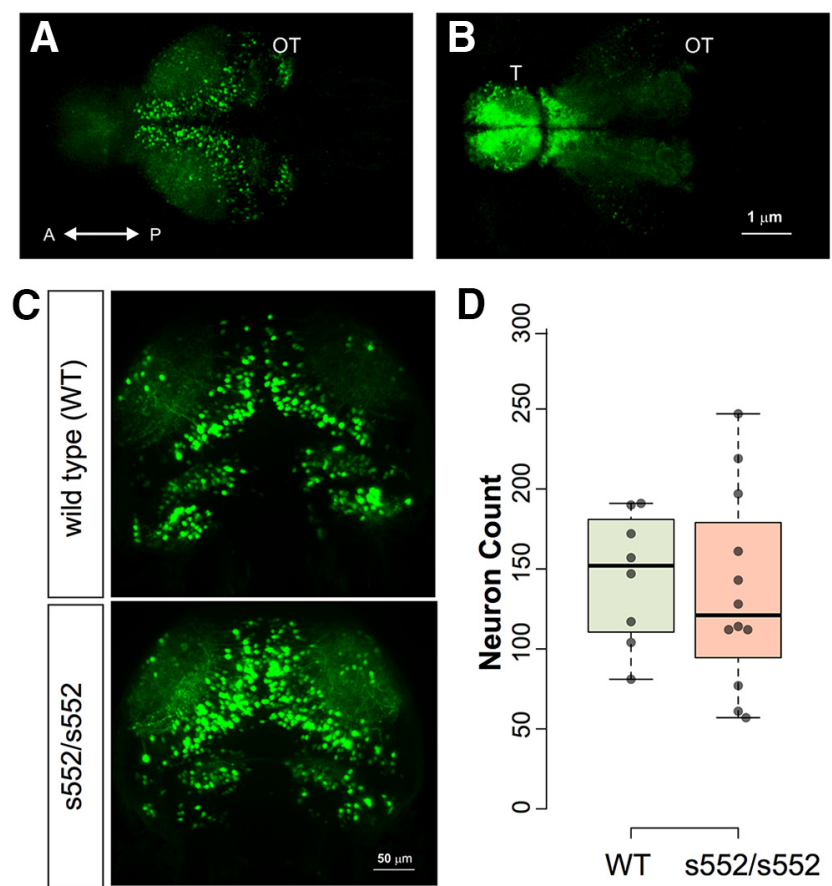

Figure 6. No significant effects of scn1lab mutation were found in numbers of $\operatorname{Tg}(1.4 d l \times 5 a-d l \times 6 a: G F P)$ neurons. Neurons were counted by light-sheet microscopy in 5-dpf larvae, followed by 3D image segmentation and quantification of discrete objects. Sample images are shown illustrating GFP fluorescence detected in optic tectum $(\boldsymbol{A})$ and telencephalon $(\boldsymbol{B})$. Representative images $(\boldsymbol{C})$ are

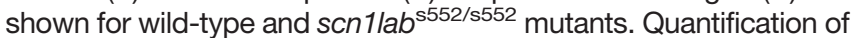
cell numbers is shown in $(\boldsymbol{D})$ as dot plots with boxplot indicating median, quartiles, and whiskers extending to the furthest point within 1.5 IQR. No significant effect of genotype was detected.

arena. Our findings correspond directly to the efficacy of these drugs at this concentration in reducing behavioral measures of seizures, as shown in previous papers. The zebrafish open field test, like the mouse equivalent, has clear limitations as an assay of cognitive function, and should be interpreted with caution as a measure of anxiety since many factors can influence open field behavior (Walsh and Cummins, 1976). Several other cognitive assays have been reported for adult zebrafish (Meshalkina et al., 2017) but are not reliably established for larvae. Overall, our results suggest that modifications to the open field assay were important for revealing behavioral deficits and could be applied to a variety of larval zebrafish mutant models.

\section{Pharmacology}

Valproic acid, diazepam, trazodone, and clemizole have all been studied for antiepileptic activity in scn1lab zebrafish larvae (Baraban et al., 2013; Griffin et al., 2017). For these drugs, effects in wild-type zebrafish on diurnal rhythms (Rihel et al., 2010) or other aspects of locomotion (Herrmann, 1993; Richendrfer et al., 2012; Baraban et al., 2013) have also been investigated. Valproic acid, a broad spectrum antiepileptic drug (Tomson et al., 2016) commonly used in DS (Chiron and Dulac, 2011), exerts protective effects in larval or adult zebrafish exposed to the chemoconvulsant pentylenetetrazole: (1) decreasing behavioral or electrographic seizure activity and (2) improv- ing deficits in learning of a passive avoidance response (Lee et al., 2010). Valproic acid has also been shown to increase "waking" activity in wild-type larvae, with a lowest effective dose of $15 \mu \mathrm{M}$ (Rihel et al., 2010). Although valproic acid at a concentration of $1 \mathrm{mM}$ exerted antiepileptic activity in scn1/ab ${ }^{5552 / s 552}$ mutant larvae (Baraban et al., 2013), no significant effect on behavior was observed here with valproic acid at a concentration of $250 \mu \mathrm{M}$. Trazodone, a drug commonly prescribed for insomnia and depression (Rickels et al., 1993; Mendelson, 2005), potentiates the high-speed movements caused by light flash in larval zebrafish (Koseki et al., 2014), and can increase rest (Rihel et al., 2010), but had no significant effects on the behaviors we assayed in the range of concentrations we tested (2.5-250 $\mu \mathrm{M})$. Diazepam, a benzodiazepine and antiepileptic drug, decreases locomotor activity, seizures, and measures of anxiety in wild-type zebrafish larvae (Zhdanova et al., 2001; Baraban et al., 2005; Schnörr et al., 2012). Diazepam has been tested at a range of concentrations from $10 \mathrm{nM}$ up to $1 \mathrm{mM}$ in larval zebrafish (Zhdanova et al., 2001; Baraban et al., 2005; Richendrfer et al., 2012; Baraban et al., 2013; Griffin et al., 2017). We found that $250 \mu \mathrm{M}$ diazepam significantly decreased locomotion in an open field test of the scn1/ab $b^{5552 / s 552}$ mutant larvae, extending previous results that showed nearly complete elimination of movements at a $100 \mu \mathrm{M}$ concentration, compared to minimal effects at a $1 \mu \mathrm{M}$ concentration (Zhdanova et al., 2001; Baraban et al., 2005). An even higher concentration of clemizole $(667 \mu \mathrm{M})$ led to nearly complete elimination of movement in scn1/ab $b^{5552 / s 552}$ mutants following a brief exposure (Baraban et al., 2013). Clemizole, a first-generation antihistamine recently identified as a potential antiepileptic drug acting on serotonin receptors in scn1lab ${ }^{\mathrm{s5} 52 / \mathrm{s5} 52}$ mutant larvae (Baraban et al., 2013; Griffin et al., 2017), decreased behavioral activity in the hyperactive scn1labs552/s552 larvae in both the diurnal and open field assays. Clemizole had no significant effects on locomotion at concentrations between $6.25 \mu \mathrm{M}$ and $50 \mu \mathrm{M}$ (Baraban et al., 2013). Similarly, clemizole can also increase "rest" activity in wild-type larvae (Rihel et al., 2010), supporting our finding of decreased nighttime locomotion in mutant larvae.

Caffeine, an adenosine receptor antagonist, is thought to produce anxiogenic effects in fish, rodents, and humans. Larval zebrafish exposed to caffeine at $100 \mathrm{mg} / \mathrm{l}$ $(515 \mu \mathrm{M})$ exhibited decreased locomotor activity and reduced swim speed in the open field test (Maximino et al., 2011; Richendrfer et al., 2012). A locomotor depressive effect of high concentrations of caffeine has also been observed in rodents (Finn and Holtzman, 1986; Svenningsson et al., 1995). Our control studies using $250 \mu \mathrm{M}$ caffeine are consistent with these reports that high concentrations of caffeine will decrease locomotor activity in wild-type larval zebrafish and support a conclusion that features of exploration and anxiety may be conserved between larval zebrafish and mammals.

\section{Interneuron density}

Interneuron defects are thought to be responsible for pathology in DS patients (Yu et al., 2006; Ogiwara et al., 2007; Mistry et al., 2014). Deficits in GABA-mediated 
inhibition may reflect changes in the number of inhibitory synapses or neurons. Using in vivo light sheet microscopy and an interneuron reporter line (i.e., dlx5/6:GFP) we found no difference in the number of GFP-positive neurons in scn1/ab $b^{\$ 552 / s 552}$ mutant larvae and control siblings. As these GFP cells are primarily GABAergic interneurons (Robles et al., 2011), our data suggest that interneurons are present in normal abundance at these early stages of development. Consistent with our findings in a zebrafish model, differences in interneuron density in mouse models of Scn1a deficiency, or patients with DS, have not been reported.

\section{Conclusion}

Some of the greatest advantages of in vivo disease modeling using larval zebrafish are the ease of genetic modifications (Varshney et al., 2013; Gagnon et al., 2014; $\mathrm{Li}$ et al., 2016), the broad range of behavioral assays available (Brockerhoff et al., 1995; Budick and O'Malley, 2000; Fero et al., 2011), and the scalability for phenotypebased drug screening (Rihel et al., 2010; Gut et al., 2013; Dinday and Baraban, 2015; Bruni et al., 2016). As demonstrated here, clinically relevant comorbidities such as sleep, movement disorders, and anxiety can be efficiently assayed in a larval zebrafish model of DS, despite concerns that "lower model organisms" such as zebrafish would not allow assessment of comorbid symptoms (EpiPM Consortium, 2015). Moreover, these assays combined with the unique attributes of larval zebrafish for higher throughput drug screening (e.g., large clutch sizes, multi-well readouts, and small-molecule permeation), can be used for the rapid identification of drugs that reduce behavioral deficits.

Note Added in Proof: The commercial interest was accidentally left off the title page of the Early Release version published August 3, 2017. The commercial interest has now been included in the "Disclosures" section.

\section{References}

Ablain J, Zon LI (2013) Of fish and men: using zebrafish to fight human diseases. Trends Cell Biol 23:584-586. CrossRef Medline Ahmad F, Richardson MK (2013) Exploratory behaviour in the open field test adapted for larval zebrafish: impact of environmental complexity. Behav Processes 92:88-98. CrossRef Medline

Baraban SC, Dinday MT, Hortopan GA (2013) Drug screening in Scn1a zebrafish mutant identifies clemizole as a potential Dravet syndrome treatment. Nat Commun 4:2410. CrossRef Medline

Baraban SC, Taylor MR, Castro PA, Baier H (2005) Pentylenetetrazole induced changes in zebrafish behavior, neural activity and c-fos expression. Neuroscience 131:759-768. CrossRef Medline

Brockerhoff SE, Hurley JB, Janssen-Bienhold U, Neuhauss SC, Driever W, Dowling JE (1995) A behavioral screen for isolating zebrafish mutants with visual system defects. Proc Natl Acad Sci USA 92:10545-10549. Medline

Bruni G, Rennekamp AJ, Velenich A, McCarroll M, Gendelev L, Fertsch E, Taylor J, Lakhani P, Lensen D, Evron T, Lorello PJ, Huang XP, Kolczewski S, Carey G, Caldarone BJ, Prinssen E, Roth BL, Keiser MJ, Peterson RT, Kokel D (2016) Zebrafish behavioral profiling identifies multitarget antipsychotic-like compounds. Nat Chem Biol 12:559-566.

Budick SA, O'Malley DM (2000) Locomotor repertoire of the larval zebrafish: swimming, turning and prey capture. J Exp Biol 203: 2565-2579.
Cahill GM, Hurd MW, Batchelor MM (1998) Circadian rhythmicity in the locomotor activity of larval zebrafish. Neuroreport 9:34453449. CrossRef

Catterall WA (2014) Sodium channels, inherited epilepsy, and antiepileptic drugs. Annu Rev Pharmacol Toxicol 54:317-338. CrossRef Medline

Chiron C, Dulac O (2011) The pharmacologic treatment of Dravet syndrome. Epilepsia 52 [Suppl2]:72-75. CrossRef Medline

Claes L, Del-Favero J, Ceulemans B, Lagae L, Van Broeckhoven C, De Jonghe $P$ (2001) De novo mutations in the sodium-channel gene SCN1A cause severe myoclonic epilepsy of infancy. Am J Hum Genet 68:1327-1332. CrossRef Medline

Deciphering Developmental Disorders Study (2015) Large-scale discovery of novel genetic causes of developmental disorders. Nature 519:223-228.

Depienne C, Trouillard O, Saint-Martin C, Gourfinkel-An I, Bouteiller D, Carpentier W, Keren B, Abert B, Gautier A, Baulac S, Arzimanoglou A, Cazeneuve C, Nabbout R, LeGuern E (2009) Spectrum of SCN1A gene mutations associated with Dravet syndrome: analysis of 333 patients. J Med Genet 46:183-191. CrossRef Medline

Dhamija R, Erickson MK, St Louis EK, Wirrell E, Kotagal S (2014) Sleep abnormalities in children with Dravet syndrome. Pediatr Neurol 50:474-478. CrossRef Medline

Dichgans M, Freilinger T, Eckstein G, Babini E, Lorenz-Depiereux B, Biskup S, Ferrari MD, Herzog J, van den Maagdenberg AM, Pusch M, Strom TM (2005) Mutation in the neuronal voltage-gated sodium channel SCN1A in familial hemiplegic migraine. Lancet 366: 371-377. CrossRef

Dinday MT, Baraban SC (2015) Large-Scale Phenotype-Based Antiepileptic Drug Screening in a Zebrafish Model of Dravet Syndrome(1,2,3). eNeuro 2(4). CrossRef Medline

Dravet C (2011) The core Dravet syndrome phenotype. Epilepsia 52 [Suppl2]:3-9. CrossRef Medline

Duflocq A, Le Bras B, Bullier E, Couraud F, Davenne M (2008) Nav1.1 is predominantly expressed in nodes of Ranvier and axon initial segments. Mol Cell Neurosci 39:180-192. CrossRef Medline

Elbaz I, Foulkes NS, Gothilf Y, Appelbaum L (2013) Circadian clocks, rhythmic synaptic plasticity and the sleep-wake cycle in zebrafish. Front Neural Circuits 7:9. CrossRef Medline

EpiPM Consortium (2015) A roadmap for precision medicine in the epilepsies. Lancet Neurol 14:1219-1228. CrossRef

Escayg A, MacDonald BT, Meisler MH, Baulac S, Huberfeld G, An-Gourfinkel I, Brice A, LeGuern E, Moulard B, Chaigne D, Buresi C, Malafosse A (2000) Mutations of SCN1A, encoding a neuronal sodium channel, in two families with GEFS+2. Nat Genet 24:343345. CrossRef Medline

Fero K, Yokogawa T, Burgess HA (2011) The behavioral repertoire of larval zebrafish. In: Zebrafish models in neurobehavioral research (Kalueff AV, Cachat JM, eds), pp 249-29. Totowa: Humana Press.

Finn IB, Holtzman SG (1986) Tolerance to caffeine-induced stimulation of locomotor activity in rats. J Pharmacol Exp Ther 238:542546. Medline

Gagnon JA, Valen E, Thyme SB, Huang P, Akhmetova L, Pauli A, Montague TG, Zimmerman S, Richter C, Schier AF (2014) Efficient mutagenesis by Cas9 protein-mediated oligonucleotide insertion and large-scale assessment of single-guide RNAs. PLoS One 9:e98186. CrossRef Medline

Gataullina S, Dulac O (2017) From genotype to phenotype in Dravet disease. Seizure 44:58-64.

Genton P, Velizarova R, Dravet C (2011) Dravet syndrome: the long-term outcome. Epilepsia 52 [Suppl2]:44-49. CrossRef Medline

Ghanem N, Jarinova O, Amores A, Long Q, Hatch G, Park BK, Rubenstein JL, Ekker M (2003) Regulatory roles of conserved intergenic domains in vertebrate Dlx bigene clusters. Genome Res 13:533-543. CrossRef Medline

Gordon D, Merrick D, Auld V, Dunn R, Goldin AL, Davidson N, Catterall WA (1987) Tissue-specific expression of the RI and RII sodium channel subtypes. Proc Natl Acad Sci USA 84:8682-8686. Medline 
Griffin A, Hamling KR, Knupp K, Hong S, Lee LP, Baraban SC (2017) Clemizole and modulators of serotonin signalling suppress seizures in Dravet syndrome. Brain 140:669-683.

Grone BP, Baraban SC (2015) Animal models in epilepsy research: legacies and new directions. Nat Neurosci 18:339-343. CrossRef Medline

Grone BP, Marchese M, Hamling KR, Kumar MG, Krasniak CS, Sicca F, Santorelli FM, Patel M, Baraban SC (2016) Epilepsy, behavioral abnormalities, and physiological comorbidities in syntaxin-binding protein 1 (STXBP1) mutant zebrafish. PLoS One 11:e0151148. CrossRef Medline

Gut P, Baeza-Raja B, Andersson O, Hasenkamp L, Hsiao J, Hesselson D, Akassoglou K, Verdin E, Hirschey MD, Stainier DY (2013) Whole-organism screening for gluconeogenesis identifies activators of fasting metabolism. Nat Chem Biol 9:97-104. CrossRef Medline

Han S, Yu FH, Schwartz MD, Linton JD, Bosma MM, Hurley JB, Catterall WA, de la Iglesia $\mathrm{HO}$ (2012a) $\mathrm{Na}(\mathrm{V}) 1.1$ channels are critical for intercellular communication in the suprachiasmatic nucleus and for normal circadian rhythms. Proc Natl Acad Sci USA 109:E368-E377.

Han S, Tai C, Westenbroek RE, Yu FH, Cheah CS, Potter GB, Rubenstein JL, Scheuer T, de la Iglesia HO, Catterall WA (2012b) Autistic-like behaviour in Scn1a+/- mice and rescue by enhanced GABA-mediated neurotransmission. Nature 489:385-390.

Harkin LA, McMahon JM, Iona X, Dibbens L, Pelekanos JT, Zuberi SM, Sadleir LG, Andermann E, Gill D, Farrell K, Connolly M, Stanley T, Harbord M, Andermann F, Wang J, Batish SD, Jones JG, Seltzer WK, Gardner A; Infantile Epileptic Encephalopathy Referral Consortium, et al. (2007) The spectrum of SCN1A-related infantile epileptic encephalopathies. Brain 130:843-852. CrossRef Medline

Herrmann K (1993) Effects of the anticonvulsant drug valproic acid and related substances on the early development of the zebrafish (Brachydanio rerio). Toxicol in Vitro 7:41-54. Medline

Hong S, Lee P, Baraban SC, Lee LP (2016) A novel long-term, multi-channel and non-invasive electrophysiology platform for zebrafish. Sci Rep 6:28248. CrossRef Medline

Ito S, Ogiwara I, Yamada K, Miyamoto H, Hensch TK, Osawa M, Yamakawa K (2013) Mouse with Nav1.1 haploinsufficiency, a model for Dravet syndrome, exhibits lowered sociability and learning impairment. Neurobiol Dis 49:29-40. CrossRef Medline

Kalume F, Westenbroek RE, Cheah CS, Yu FH, Oakley JC, Scheuer T, Catterall WA (2013) Sudden unexpected death in a mouse model of Dravet syndrome. J Clin Invest 123:1798-1808. CrossRef Medline

Kaplan DI, Isom LL, Petrou S (2016) Role of sodium channels in epilepsy. Cold Spring Harb Perspect Med 6. CrossRef

Koseki N, Deguchi J, Yamashita A, Miyawaki I, Funabashi H (2014) Establishment of a novel experimental protocol for drug-induced seizure liability screening based on a locomotor activity assay in zebrafish. J Toxicol Sci 39:579-600. Medline

Kumar MG, Rowley S, Fulton R, Dinday MT, Baraban SC, Patel M (2016) Altered glycolysis and mitochondrial respiration in a zebrafish model of Dravet syndrome. eNeuro 3. CrossRef

Lee Y, Kim D, Kim YH, Lee H, Lee CJ (2010) Improvement of pentylenetetrazol-induced learning deficits by valproic acid in the adult zebrafish. Eur J Pharmacol 643:225-231. CrossRef Medline

Li M, Zhao L, Page-McCaw PS, Chen W (2016) Zebrafish genome engineering using the CRISPR-Cas9 system. Trends Genet 32: 815-827. CrossRef Medline

Liew WC, Orbán L (2014) Zebrafish sex: a complicated affair. Brief Funct Genomics 13:172-187. CrossRef Medline

Martin P, Rautenstrau $\beta$ B, Abicht A, Fahrbach J, Koster S (2010) Severe myoclonic epilepsy in infancy - adult phenotype with bradykinesia, hypomimia, and perseverative behavior: report of five cases. Mol Syndromol 1:231-238. CrossRef

Maximino C, Lima MG, Olivera KR, Picanço-Diniz DL, Herculano AM (2011) Adenosine A1, but not A2, receptor blockade increases anxiety and arousal in zebrafish. Basic Clin Pharmacol Toxicol 109:203-207. CrossRef

Meisler MH, Kearney JA (2005) Sodium channel mutations in epilepsy and other neurological disorders. J Clin Invest 115:20102017. CrossRef Medline

Mendelson WB (2005) A review of the evidence for the efficacy and safety of trazodone in insomnia. J Clin Psychiatry 66:469-476. Medline

Meshalkina DA, Kizlyk MN, Kysil EV, Collier AD, Echevarria DJ, Abreu MS, Barcellos LJ, Song C, Kalueff AV (2017) Understanding zebrafish cognition. Behav Processes 141:229-241.

Mistry AM, Thompson CH, Miller AR, Vanoye CG, George AL Jr, Kearney JA (2014) Strain- and age-dependent hippocampal neuron sodium currents correlate with epilepsy severity in Dravet syndrome mice. Neurobiol Dis 65:1-11. CrossRef

Nolan KJ, Camfield CS, Camfield PR (2006) Coping with Dravet syndrome: parental experiences with a catastrophic epilepsy. Dev Med Child Neurol 48:761-765. CrossRef Medline

Novak AE, Taylor AD, Pineda RH, Lasda EL, Wright MA, Ribera AB (2006a) Embryonic and larval expression of zebrafish voltagegated sodium channel alpha-subunit genes. Dev Dyn 235:19621973.

Novak AE, Jost MC, Lu Y, Taylor AD, Zakon HH, Ribera AB (2006b) Gene duplications and evolution of vertebrate voltage-gated sodium channels. J Mol Evol 63:208-221.

Oakley JC, Kalume F, Yu FH, Scheuer T, Catterall WA (2009) Temperature- and age-dependent seizures in a mouse model of severe myoclonic epilepsy in infancy. Proc Natl Acad Sci USA 106:3994-3999. CrossRef Medline

Ogiwara I, Miyamoto H, Morita N, Atapour N, Mazaki E, Inoue I, Takeuchi T, Itohara S, Yanagawa Y, Obata K, Furuichi T, Hensch TK, Yamakawa K (2007) Nav1.1 localizes to axons of parvalbuminpositive inhibitory interneurons: a circuit basis for epileptic seizures in mice carrying an Scn1a gene mutation. J Neurosci 27: 5903-5914. CrossRef Medline

Papale LA, Makinson CD, Christopher Ehlen J, Tufik S, Decker MJ, Paul KN, Escayg A (2013) Altered sleep regulation in a mouse model of SCN1A-derived genetic epilepsy with febrile seizures plus (GEFS+). Epilepsia 54:625-634. CrossRef

Pietri T, Roman AC, Guyon N, Romano SA, Washbourne P, Moens CB, de Polavieja GG, Sumbre G (2013) The first mecp2-null zebrafish model shows altered motor behaviors. Front Neural Circuits 7:118. CrossRef Medline

R Core Team (2016) R: a language and environment for statistical computing. Vienna: R Foundation for Statistical Computing.

Richendrfer H, Pelkowski SD, Colwill RM, Creton R (2012) On the edge: pharmacological evidence for anxiety-related behavior in zebrafish larvae. Behav Brain Res 228:99-106.

Rickels K, Downing R, Schweizer E, Hassman H (1993) Antidepressants for the treatment of generalized anxiety disorder. A placebocontrolled comparison of imipramine, trazodone, and diazepam. Arch Gen Psychiatry 50:884-895. Medline

Rihel J, Prober DA, Arvanites A, Lam K, Zimmerman S, Jang S, Haggarty SJ, Kokel D, Rubin LL, Peterson RT, Schier AF (2010) Zebrafish behavioral profiling links drugs to biological targets and rest/wake regulation. Science 327:348-351. CrossRef Medline

Robles E, Smith SJ, Baier H (2011) Characterization of genetically targeted neuron types in the zebrafish optic tectum. Front Neural Circuits 5:1. CrossRef Medline

Schindelin J, Arganda-Carreras I, Frise E, Kaynig V, Longair M, Pietzsch T, Preibisch S, Rueden C, Saalfeld S, Schmid B, Tinevez JY, White DJ, Hartenstein V, Eliceiri K, Tomancak P, Cardona A (2012) Fiji: an open-source platform for biological-image analysis. Nat Methods 9:676-682. CrossRef Medline

Schnörr SJ, Steenbergen PJ, Richardson MK, Champagne DL (2012) Measuring thigmotaxis in larval zebrafish. Behav Brain Res 228: 367-374. CrossRef Medline

Schoonheim PJ, Arrenberg AB, Del Bene F, Baier H (2010) Optogenetic localization and genetic perturbation of saccade-generating neurons in zebrafish. J Neurosci 30:7111-7120. CrossRef 
Sourbron J, Schneider H, Kecskés A, Liu Y, Buening EM, Lagae L, Smolders I, de Witte P (2016) Serotonergic modulation as effective treatment for Dravet syndrome in a zebrafish mutant model. ACS Chem Neurosci 7:588-598. CrossRef

Sugawara T, Mazaki-Miyazaki E, Fukushima K, Shimomura J, Fujiwara T, Hamano S, Inoue Y, Yamakawa K (2002) Frequent mutations of SCN1A in severe myoclonic epilepsy in infancy. Neurology 58:1122-1124. Medline

Svenningsson P, Nomikos GG, Fredholm BB (1995) Biphasic changes in locomotor behavior and in expression of mRNA for NGFI-A and NGFI-B in rat striatum following acute caffeine administration. J Neurosci 15:7612-7624.

Tomson T, Battino D, Perucca E (2016) Valproic acid after five decades of use in epilepsy: time to reconsider the indications of a time-honoured drug. Lancet Neurol 15:210-218.

Tuschl K, Meyer E, Valdivia LE, Zhao N, Dadswell C, Abdul-Sada A, Hung CY, Simpson MA, Chong WK, Jacques TS, Woltjer RL, Eaton S, Gregory A, Sanford L, Kara E, Houlden H, Cuno SM, Prokisch H, Valletta L, Tiranti V, et al. (2016) Mutations in SLC39A14 disrupt manganese homeostasis and cause childhood-onset parkinsonism-dystonia. Nat Commun 7:11601. CrossRef Medline

Varshney GK, Lu J, Gildea DE, Huang H, Pei W, Yang Z, Huang SC, Schoenfeld D, Pho NH, Casero D, Hirase T, Mosbrook-Davis D, Zhang S, Jao LE, Zhang B, Woods IG, Zimmerman S, Schier AF, Wolfsberg TG, Pellegrini M, et al. (2013) A large-scale zebrafish gene knockout resource for the genome-wide study of gene function. Genome Res 23:727-735. CrossRef Medline

Walsh RN, Cummins RA (1976) The Open-Field Test: a critical review. Psychol Bull 83:482-504. Medline
Wang G, Grone B, Colas D, Appelbaum L, Mourrain P (2011) Synaptic plasticity in sleep: learning, homeostasis and disease. Trends Neurosci 34:452-463. CrossRef Medline

Waxman SG, Merkies IS, Gerrits MM, Dib-Hajj SD, Lauria G, Cox JJ, Wood JN, Woods CG, Drenth JP, Faber CG (2014) Sodium channel genes in pain-related disorders: phenotype-genotype associations and recommendations for clinical use. Lancet Neurol 13: 1152-1160. CrossRef Medline

Westerfield M (2000) The zebrafish book. A guide for the laboratory use of zebrafish (Danio rerio), Ed 4. Eugene: University of Oregon Press.

Widmark J, Sundström G, Ocampo Daza D, Larhammar D (2011) Differential evolution of voltage-gated sodium channels in tetrapods and teleost fishes. Mol Biol Evol 28:859-871. CrossRef Medline

Wilmshurst JM, Berg AT, Lagae L, Newton CR, Cross JH (2014) The challenges and innovations for therapy in children with epilepsy. Nat Rev Neurol 10:249-260. CrossRef Medline

Yokogawa T, Marin W, Faraco J, Pézeron G, Appelbaum L, Zhang J, Rosa F, Mourrain P, Mignot E (2007) Characterization of sleep in zebrafish and insomnia in hypocretin receptor mutants. PLoS Biol 5:e277. CrossRef Medline

Yu FH, Mantegazza M, Westenbroek RE, Robbins CA, Kalume F, Burton KA, Spain WJ, McKnight GS, Scheuer T, Catterall WA (2006) Reduced sodium current in GABAergic interneurons in a mouse model of severe myoclonic epilepsy in infancy. Nat Neurosci 9:1142-1149. CrossRef

Zhdanova IV, Wang SY, Leclair OU, Danilova NP (2001) Melatonin promotes sleep-like state in zebrafish. Brain Res 903:263-268. Medline 